$\mathbb{P}$ Periodica Polytechnica

Civil Engineering

61(1), pp. 7-13, 2017

DOI: $10.3311 /$ PPci.9273

Creative Commons Attribution (i)

RESEARCH ARTICLE

\section{Application and Comparison of Two Chlorine Decay Models for Predicting Bulk Chlorine Residuals}

\author{
Sonia Al Heboos ${ }^{1 *}$, István Licskó ${ }^{1}$
}

Received 04-04-2016; revised 24-05-2016; accepted 20-06-2016

\begin{abstract}
In this study, the factors that leading to loss of chlorine residual in water distribution systems were investigated. A series of experiments performed on real water samples collected from effluent of water treatment plant before chlorination. The results showed that bulk chlorine decay rate varied significantly with the initial chlorine concentration and the organic content of water.

Further, this paper explores the performance and the potential applicability of the parallel first order model and second order model to represent the bulk chlorine reactions. The modelling and simulation study lead to define the bulk chlorine coefficients as a function of initial chlorine concentration (Co) and COD by developing mathematical equations related to these parameters.
\end{abstract}

\section{Keywords}

bulk chlorine decay, initial chlorine concentration, modelling of bulk chlorine decay

\footnotetext{
${ }^{1}$ Department of Sanitary and Environmental Engineering, Faculty of Civil Engineering,

Budapest University of Technology and Economics, H-1111 Budapest, Hungary

*Corresponding author, email: sonia@vkkt.bme.hu
}

\section{Introduction}

The disinfection is an important treatment process as a barrier against the pathogenic microorganism in water distribution system. The advantages of chlorine disinfection are well known and include such benefits as simplicity, low cost, and a broad range of effectiveness [1]. Bulk chorine demand is influenced by the components in the raw and treated water. Water treatment processes change the concentration of these components in the drinking water and are likely change the chlorine demand of water. Therefore, modelling chlorine decay is important to find input parameters that can reflect the changes in water quality characteristics [2].

Chlorine reacts with a variety of organic and inorganic compounds present in bulk water (e.g., ammonia, sulfides, iron, manganese, and organic matter), and with pipe walls material or sediments exist at these walls in the network. Chlorine reactions with organic material provides some by-products such as trihalo methane (THM), haloacetic acids (HAAs) and other compounds that can be assessed with the adsorbable organic halogen $(\mathrm{AOX})$ measurement. AOX are mutagenic products and may have harmful effects on human health and the environment [3]. However, it is well known that chlorination is not the best solution for disinfection the water if it has high organic compounds concentrations [4].

Chlorine decay models help in understanding chlorine reactions with contaminants in the bulk phase and with biofilm and pipe wall surfaces during water distribution. Few models have been developed to study chlorine kinetic in bulk phase [5].

The aims of this work are (1) investigating the influence of the initial chlorine concentration and the organic content on bulk chlorine decay (2) studying the ability of parallel first order model and second order model to simulate the bulk chlorine decay in several water samples with different organic matter contents and with a wide range of initial chlorine concentrations (3) comparing the efficiency of each model in predicting the bulk chlorine residual (4) modelling the bulk reaction rate coefficients and parameters for each model as a function of initial chlorine concentration and COD. 


\section{Modelling of bulk Chlorine decay}

Generally, bulk Chlorine decay can be divided into first order and non-first order reaction kinetic models. One of the conventional chlorine decay kinetic models is the first order model. It includes expressions to describe reactions occurring in the bulk fluid [6]. The differential form of this model is given by:

$$
\frac{d C}{d t}=-k C
$$

Where $k$ is the decay rate ( $1 /$ time) and $C$ is the chlorine concentration at a certain time $t(\mathrm{mg} / \mathrm{l})$. Several attempts [7] were made to upgrade and compensate the defects of the simple first order model. The yielded models were: the n-th order model, the limited first order model, and the parallel first order model which assumes that chlorine concentration can be divided in two parts; each part is decaying according to first order model. A fraction of the initial chlorine concentration $\left(x C_{o}\right)$ decays with rate constant $\left(k_{1}\right)$ and the remainder $\left[(1-x) C_{o}\right]$ decays with different rate $\left(k_{2}\right)$. The differential form for this model is given by (2):

$$
\frac{d C}{d t}=-k_{1} C_{1}-k_{2} C_{2}
$$

And the integrated form is:

$$
\begin{gathered}
C(t)=C_{O} x e^{\left(-k_{1} t\right)}+C_{O}(1-x) e^{\left(-k_{2} t\right)} \\
C_{1}=C_{O} x,=C_{2}=C_{O}(1-x)
\end{gathered}
$$

Where, $C(t)$ is the chlorine concentration at any time $\mathrm{t}(\mathrm{mg} / \mathrm{l})$; $C_{o}$ the initial chlorine concentration $(\mathrm{mg} / \mathrm{l}) ; x$ the fraction of the chlorine demand attributed to slow reactions; $k_{1}$ the first-order rate constant for slow reactions $(1 / \mathrm{h})$; and, $k_{2}$ the first-order rate constant for rapid reactions $(1 / \mathrm{h})$.

Clark [8] developed a second order chlorine decay model which is based on the concept of reaction between chlorine and another notional substance on the assumption that the balanced reaction equation can be represented as follows (5):

$$
a A+b B \rightarrow p P
$$

Where $A$ and $B$ are reacting substances; $A$ could be representative for chlorine and $B$ a summation of all individual organic and inorganic species which potentially react with chlorine. $P$ is an overall representative for the product of the reaction. Thus, the rates of reaction are given by:

$$
\frac{d C_{A}}{d t}=-k_{A} C_{A} C_{B}, \quad \frac{d C_{B}}{d t}=-k_{B} C_{A} C_{B}
$$

Where $k_{A}$ and $k_{B}$ are the decay rates (1/time), $\mathrm{C}_{\mathrm{A}}$ and $\mathrm{C}_{\mathrm{B}}$ are the concentrations of chlorine and reactive component $(\mathrm{mg} / \mathrm{l})$, respectively, at a certain time $t$. Clark proposed an analytical solution for this model, which was the first prosperous trial for a second-order model:

$$
\begin{gathered}
C_{A}(t)=\frac{C_{A, o}(1-K)}{\left[1-K e^{(-u t)}\right]} \\
K=\frac{\left(a C_{B, o}\right)}{\left(b C_{A, o}\right)}
\end{gathered}
$$

Where, $C_{A}(t)$ is the chlorine concentration in $\mathrm{mg} / \mathrm{l}$ at time $\mathrm{t}$ [h], $K$ is dimensionless constant and $u[1 / \mathrm{h}]$ is rate constant. The value for the rate constant $(u)$ can be rewritten as follows:

$$
\begin{aligned}
& u=M(1-K), \quad M=\frac{b k_{A} C_{A, o}}{a} \\
& M>0
\end{aligned}
$$

Where, $M(1 / \mathrm{h})$ must be estimated. Clark and Sivaganesan [9] developed non-linear empirical regression models to estimate $K$ and $M$ that depend on natural water characteristics such as temperature, $\mathrm{pH}$, TOC and $C_{o}$. Boccelli [10] noticed that Clark and Sivaganesan's regression equations were inconsistent with the theoretical relationships of $K$ and $\mathrm{M}$ provided by (8) and (9), where $K$ was not linear in $1 / C_{A, 0}$ and $M$ was independent of $C_{A, 0}$.

Huang and McBean [11] found out a wrong in deriving method of equation (7). On the other hand, Fisher et al. [12] could prove that Clark equation (7) was right except of missing a negative sign, which did not have any effect on the final result.

In most of studies, bulk chlorine decay rates have been observed to affect by different factors. Powell [13] showed the dependence of bulk decay coefficient on temperature, total organic carbon (TOC), UV and the initial chlorine concentration $\left(C_{o}\right)$. On the other hand, Vasconcelos [1] reported an extensive study of the effect of temperature and total organic carbon concentration (TOC) on chlorine decay rates. They reported a linear relationship between the first order decay constant and TOC, but no data were given to verify their equation. Al-Omari [14] concluded a logarithmic relationship between the bulk chlorine $k_{b}$, the initial chlorine concentrations $\left(C_{o}\right)$, TOC and temperature $(\mathrm{T})$.

In this work, the parallel first- order and second -order models, have been examined and the result of calibration has been compared with the measured data.

\section{Methodology and Experimental Work 3.1 Analysing Samples}

The experiments were applied on water samples collected from outlet of an operating water treatment plant (WTP). The treatment process in this plant has been changed since five years ago to be as follows: aeration, fluidized bed filtration with microbiological $\mathrm{NH}^{+}$removal, UV disinfection, rapid sand filtration, disinfection by chlorine gas, treated water tanks and safety filter (Fig. 1). A full-scale analysing was performed on chemical, physical and microbiological water quality data 
collected by the water utility over 10 years. The analysing results showed that concentrations of ammonium, iron and manganese in the finished treated water (TW) decreased significantly after replacement the treatment technology. In contrast, increasing in THM concentrations was observed, this rising could be attributed to increasing in free chlorine concentrations and decreasing in chloramine concentrations which was dominated before. However, increasing of THM concentration did not exceed the Hungarian Standard limit for THM (50 $\mu \mathrm{g} / 1)$.

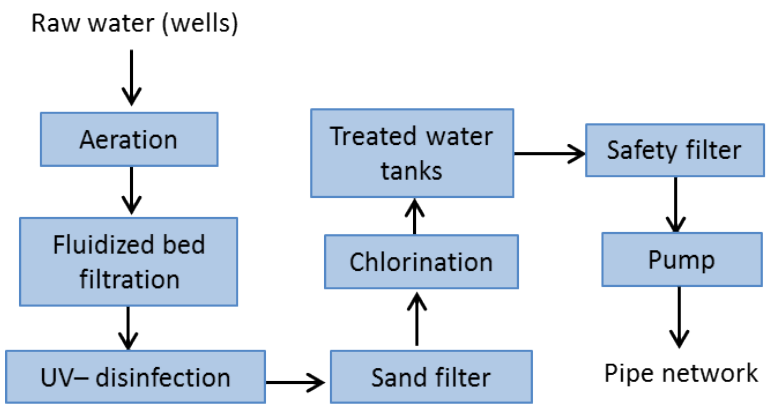

Fig. 1 Treatment processes in the studied water treatment plant

\subsection{Experiments}

The effect of the initial chlorine concentration was studied by adding chlorine to finished treated water samples (TW) to achieve five different initial concentrations: 1.0, 1.5, 1.8, 2.0 and $2.5 \mathrm{mg} / \mathrm{l}$, then the residual chlorine concentrations were measured by bottle test and plotted versus time to show the kinetic of chlorine disintegration. Due to the observed increasing in THM concentration in the studied water supply system, the effect of the natural organic content on bulk chlorine decay was studied. In this work, the organic content was evaluated by determining the permanganate index and indicated as COD. In most of developing countries, the measurement possibility of the total organic carbon (TOC) is not available as the situation in the studied water system. However, TW samples were diluted by distilled water (DW) to vary the COD concentrations. The dilution ratios of the distilled water to the treated water (DW: TW) were defined as follow: 1:1, 1:2, 1:3, 2:1 and 3:1. COD concentration was measured in each diluted sample by using potassium permanganate method $\left(\mathrm{KMnO}_{4}, \mathrm{~N} \mathrm{0.01)}\right.$. For every measurement, a blank titration with distilled water as sample was run. COD values in the diluted samples have been ranged between 0.8 to $1.6 \mathrm{mg} / 1$.

The diluted samples were chlorinated by using sodium hypochlorite solution. They dosed in 2 liter glass bottles, and then carefully distributed into $100 \mathrm{ml}$ glass vials and tightly closed with caps. Two initial chlorine concentrations 1.2 and $1.5 \mathrm{mg} / \mathrm{l}$ have been used to dose each sample. Prior to chlorination, the strength of the dosing solution was measured several times to ensure the accuracy. A blank sample was prepared using the same amount of deionized water and chlorinated under the same conditions. This blank was used as a reference to establish the initial chlorine concentration. In each sample, the residual chlorine concentration was measured by using the DPD (N, N-diethyl-p-phenylenediamine) method. The colour which developed was measured in photometer (Nanocolor 400 D). In this study, 16 set of data were observed through the tests, 12 of them were selected randomly for model calibration and the remaining four set was used for model validation.

\section{Result and discussion}

As it was mentioned previously, the parallel first order model and second order model have been applied on the experimental data. The parallel first order model characterized the chlorine decay by two phases: an initial fast phase where fast reactions occur with coefficient rate $k_{2}$, followed by a second, slower phase with coefficient rate $k_{1}$, where less reactive species react with the disinfectant. However, the model coefficients $\left(k_{1}, k_{2}\right.$, $x$ ) which are presented in Eq. (3) were calculated by optimizing their values to minimize the sum of the squared errors between the modelled and observed chlorine concentrations, then, plotted versus the independent variables ( $C_{o}$ and COD).

Figures 2 and 3 present the linear relationship between parallel first order model coefficients and the reciprocal of initial chlorine concentration $\left(C_{o}\right)$.

The determination coefficients $\left(\mathrm{R}^{2}\right)$ were found to be 0.92 for both the rapid and slow decay coefficients, which show very strong relationship between $1 / C_{o}, k_{1}$ and $k_{2}$. This finding agrees with those of [13] and [15]. As well, it was observed a clear increasing in the fraction of chlorine slowly reacting $(x)$ by increasing the initial chlorine concentration $\left(C_{o}\right)$ as be shown in Fig. 4 and thus, the fraction of chlorine rapidly reacting $(1-x)$ was decreased by $C_{o}$ increasing.

Figures 5 and 6 illustrated the influence of COD on $k_{1}, k_{2}$ and $x$ in case of the initial chlorine concentrations 1.2 and $1.5 \mathrm{mg} / \mathrm{l}$. It was observed that bulk chlorine decay coefficients have been to increase by COD increasing. However, the results showed exponential relationships between $k_{1}, k_{2}$ and COD. These observed relationships were stronger in case of $\mathrm{k}_{2}$ with $\left(\mathrm{R}^{2}>0.9\right)$ comparing to the correlations between $k_{1}$ and COD with $\mathrm{R}^{2}>0.77$. This could indicate to the importance of organic compounds reactions with chlorine in the fast phase of decay.

Concerning $x$, an inverse relationship was found between this fraction and COD. For high COD concentrations, values of chlorine fraction slowly reacting $(x)$ were low. As it can be seen from Fig. 7, the correlation between COD and $x$ was good $\left(\mathrm{R}^{2}=0.97\right)$ in case of high initial chlorine concentration $\left(C_{o}=1.5\right) \mathrm{mg} / \mathrm{l}$, and on the other hand, it was poor $\left(\mathrm{R}^{2}=0.58\right)$ in case of low $C_{o}(1.2) \mathrm{mg} / \mathrm{l}$. 


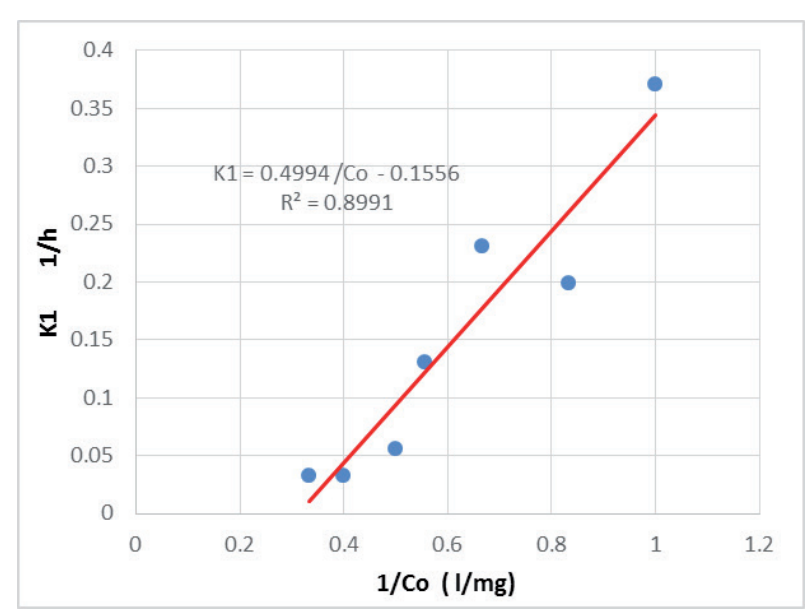

Fig. 2 Relationship between $k_{1}$ and 1/Co

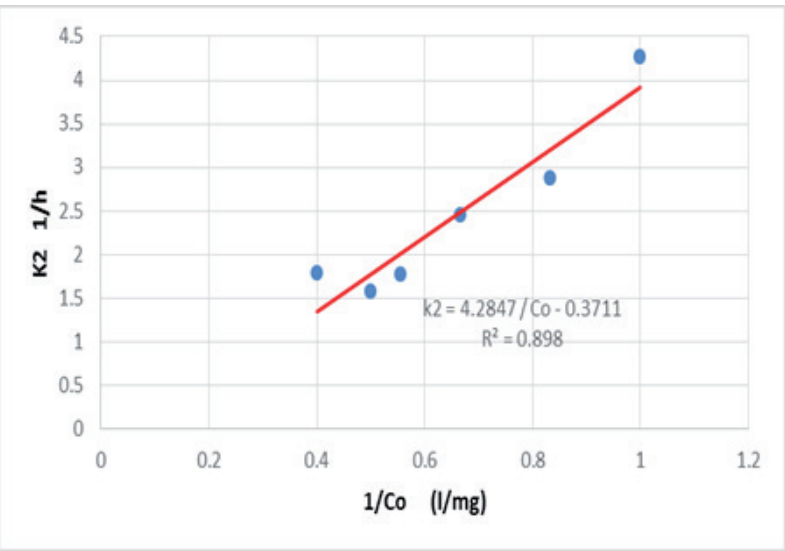

Fig. 3 Relationship between $k_{2}$ and 1/Co

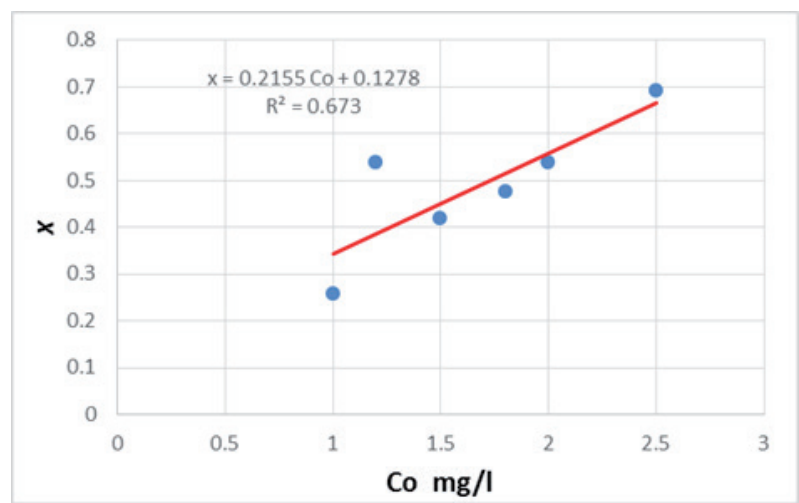

Fig. 4 Influence of the initial chlorine concentration $\left(C_{o}\right)$ on $x$

Applying the second order model on the same experimental data, showed other results concerning the effect of $C_{o}$ and COD on the model parameters. Equation (7) was used to model the measured bulk chlorine concentration at laboratory. At first, $K$ and $M$ were determined by minimizing the sum of the squared errors between predicted and observed values of chlorine concentrations, then, the influence of $C_{o}$ and COD on these parameters was investigated. Figure 8 appears a proportional relationship between COD and $K$ for two different $C_{o}$ concentrations
$(1.2,1.5) \mathrm{mg} / \mathrm{l}$ where the determination coefficients were 0.79 and 0.69 respectively. This relation was also detected between $\mathrm{COD}$ and $M$ with $\mathrm{R}^{2}>0.76$, Fig. 9 . However, it can be seen that $K$ and $M$ values increased by increasing COD concentrations in water samples.

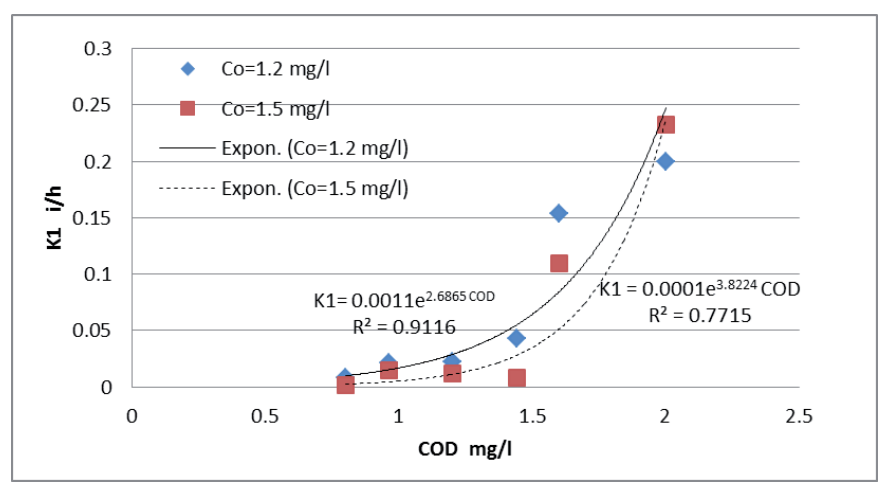

Fig. 5 The relationship between $k_{1}$ and COD

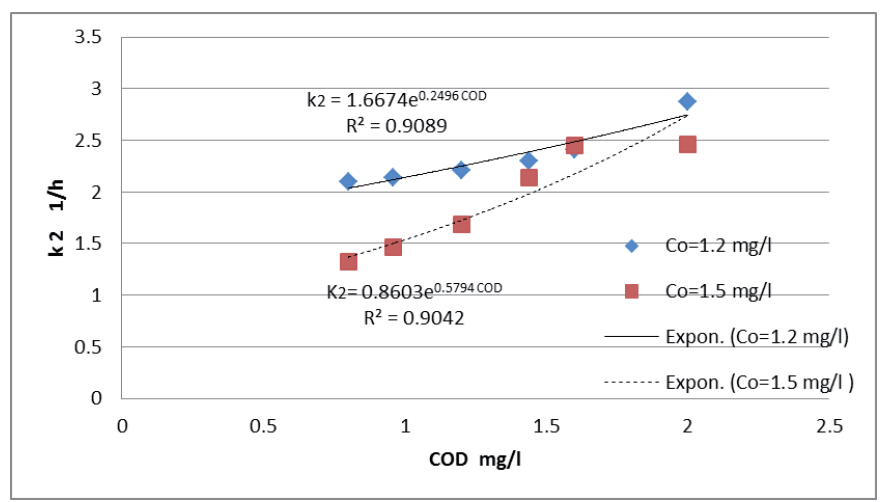

Fig. 6 The relationship between $k_{2}$ and COD

On the other hand, the influence of the initial chlorine concentration on these parameters $(K, M)$ was reported in Figs. 10 and 11. It was observed an inverse correlation between $K, M$ and $C_{o}$, where $\mathrm{R}^{2}$ was 0.72 in case of $K$ and 0.85 in case of M. Here, it was found that the parameter of second-order model $(M)$ significantly depend on the initial chlorine concentration $\left(C_{o}\right)$.

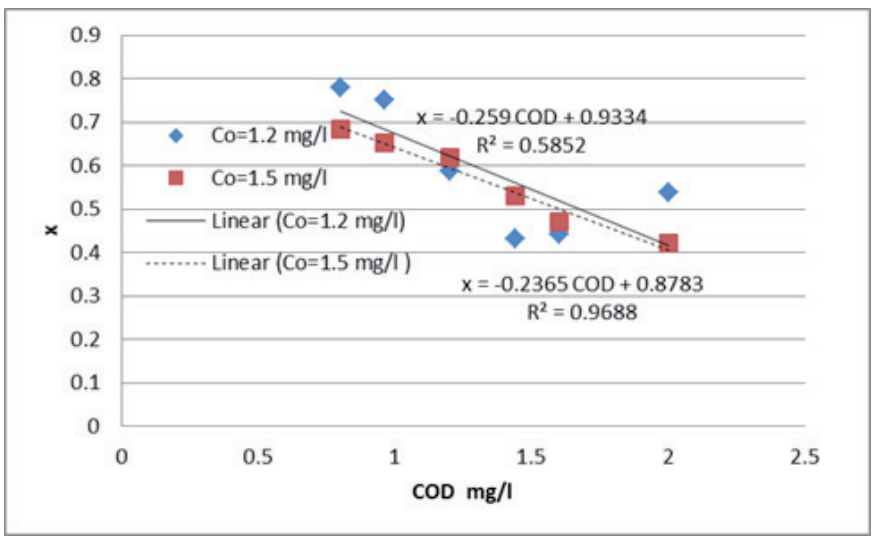

Fig. 7 The relationship between $x$ and COD 


\subsection{Modelling the combined effect of initial chlorine concentration and COD on the parameters}

In attempting to predict the coefficients of parallel first order model $\left(k_{1}, k_{2}, x\right)$ and the second order model $(K, M)$, various functional relationships have been tested to describe the behaviour of these coefficients. The initial chlorine concentration (Co) and COD were the dependent variables in the mathematical models. In this study, the bulk chlorine decay coefficients $\left(k_{1}, k_{2}\right)$ and fraction of chlorine $(x)$ of parallel first order model have been modelled as follows: (Eqs. (10), (11), (12)) :

$$
\begin{aligned}
& k_{1}=p_{1} C_{o}^{\left(-m_{1}\right)} e^{n_{1} C O D} \\
& k_{2}=p_{2} C_{o}^{\left(-m_{2}\right)} e^{n_{2} C O D} \\
& x=d_{1} C_{o}^{d_{2}} C O D^{-d_{3}}
\end{aligned}
$$

Where $\left(p_{1}, p_{2}, m_{1}, m_{2}, n_{1}, n_{2}, d_{1}, d_{2}, d_{3}\right)$ are constants and should be estimated.

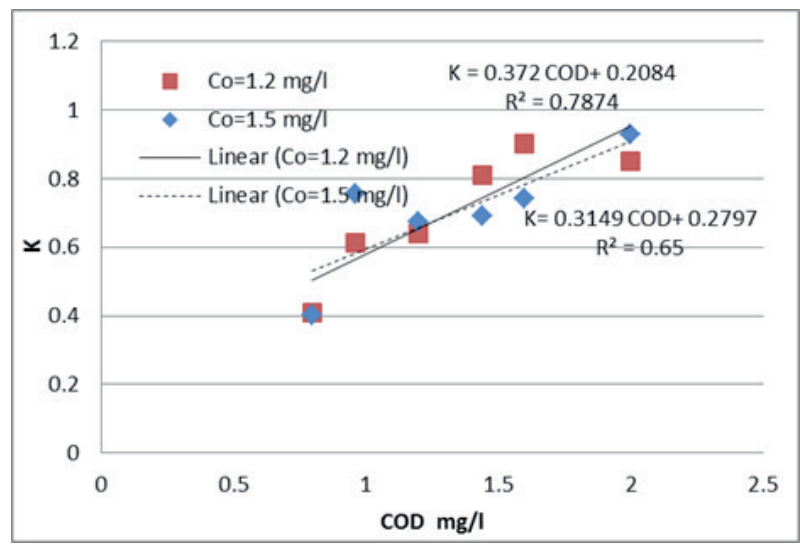

Fig. 8 Effect of COD on K

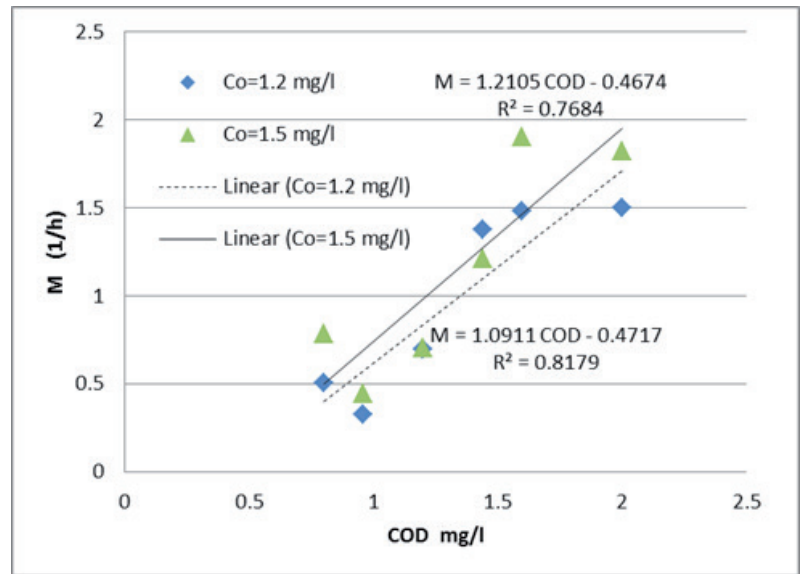

Fig. 9 Effect of COD on M

On the other hand, empirical relationships between $\mathrm{Co}$, $\mathrm{COD}$ and the second order model coefficients $(K, M)$ have been derived (Eqs. (13) and (14)) :

$$
K=f_{1} C O D^{g_{1}} C_{o}^{-h_{1}}
$$

$$
M=f_{2} C O D^{g_{2}} C_{o}^{-h_{2}}
$$

Where $\left(f_{1}, f_{2}, g_{1}, g_{2}, h_{1}, h_{2}\right)$ are constants. To estimate the previous constants, equations from 10 to 14 have been transformed into natural logarithms, and then Multiple Regression Analysis was run. The yielded equations were given by:

$$
\begin{gathered}
k_{1}=0.00057 C_{o}^{-3.2} e^{3.42 C O D} \\
k_{2}=1.53 C_{o}^{-1.02} e^{0.44 C O D} \\
x=0.52 C_{o}^{0.71} C O D^{-0.63} \\
K=0.61 C_{o}^{-0.28} C O D^{0.74} \\
M=1.29 C_{o}^{-2.33} C O D^{1.26}
\end{gathered}
$$

The determination coefficients $\left(\mathrm{R}^{2}\right)$ of the best fit between the predicted and observed $k_{1}, k_{2}, x, K$ and $M$ values were 0.95 , $0.89,0.65,0.84$ and 0.81 respectively.

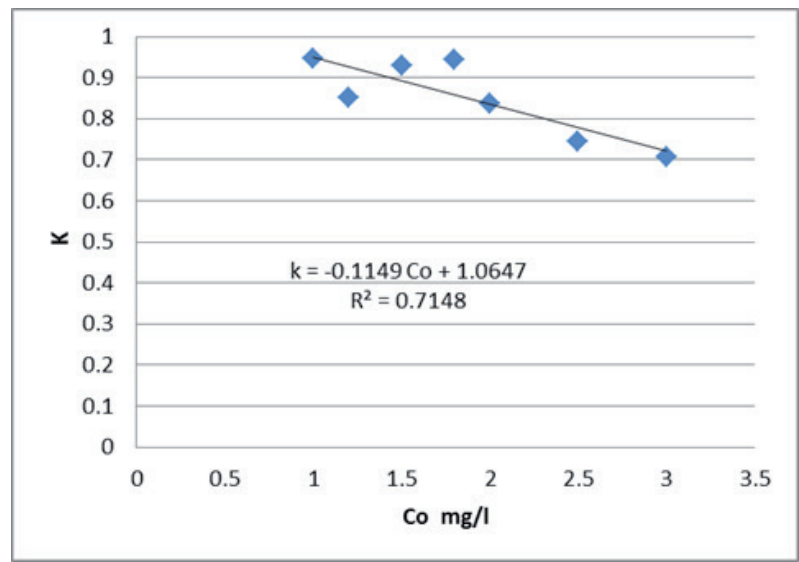

Fig. 10 Effect of $\left(C_{o}\right)$ on $\mathrm{K}$

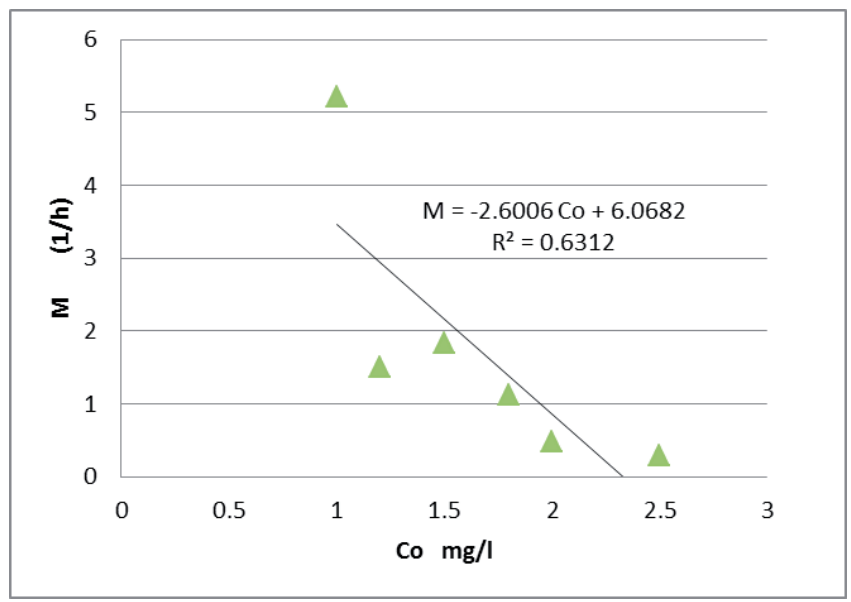

Fig. 11 Effect of $\left(C_{o}\right)$ on $\mathrm{M}$ 


\subsection{Model validation}

For models verification, the remaining set of the observed data have been used. Equations from (15) to (17) were utilized to calculate the parameters for Eq. (3), which represent the parallel first order model, and then the predicted bulk chlorine concentrations were plotted versus the observed one as it can be seen in Fig. 12. It can be seen that the parallel first order model achieved good fitting between the modelled and observed data with determination coefficient 0.79. Additionally, the second order model was applied to predict the bulk chlorine concentrations for the same set of data. In this case, the determination coefficient was higher (0.88) comparing to the parallel first order model, as well, the slope of the straight line, which represent the agreement between the predicted and the measured data, was 1.02 in case of the second order model and 1.0 for the parallel first order model, Fig. 13.

Although the differences between parallel first- and secondorder models may often be slight, it could be suggested that the second-order model is significantly better for describing chlorine decay where it has the best fit between the predicted and the observed bulk chlorine concentrations.

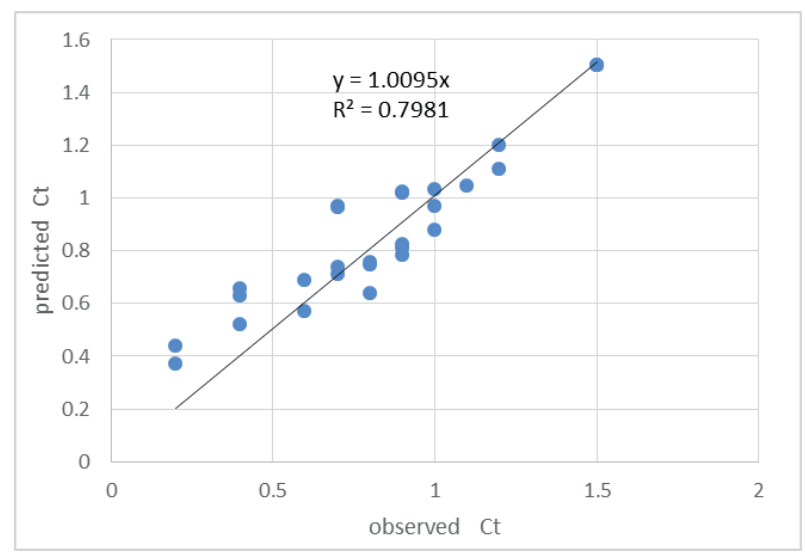

Fig. 12 Fitting between the predicted and observed bulk chlorine concentrations for parallel first order model

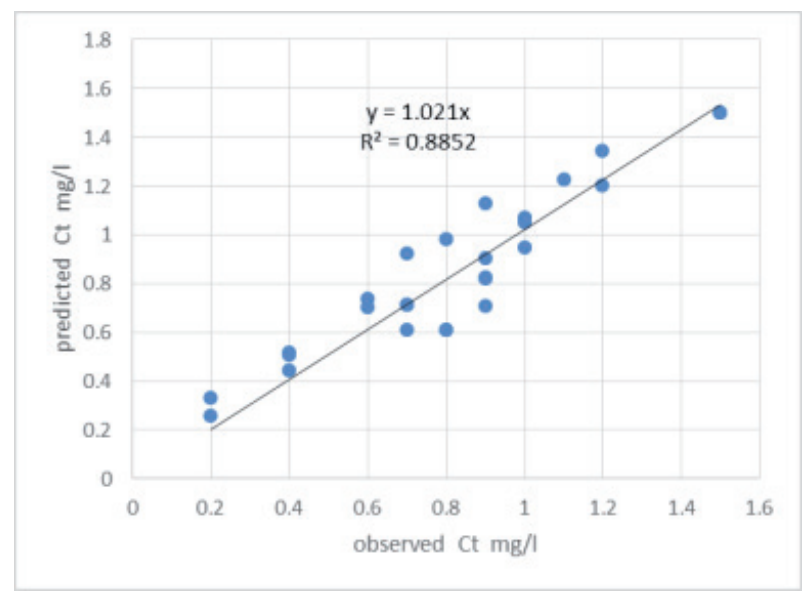

Fig. 13 Fitting between the predicted and observed bulk chlorine concentrations for second order model

\section{Conclusions}

In this work, it was found that the rate of bulk chlorine decay is influenced by the initial concentration of chlorine and organic matter. Two different kinetic models, parallel first order and second order model have been applied in this study to simulate the bulk chlorine decay. The decay coefficients of both models were observed to show significant variation with the initial chlorine concentration $\left(C_{o}\right)$ and COD of water. To account for combined effects of $C_{o}$ and COD on chlorine decay rate, empirical equations had been developed relating these parameters with constants of both parallel first order and second order model. It was found that the parameter of second order model (M) was dependent on the initial chlorine concentration $\mathrm{C}_{\mathrm{o}}$, and this result is corresponds to the theoretical relationships of M (Eq. (9)).

However, these equations could be used to update and improve the decay constants in water quality models. The relationship between chlorine decay parameters and water characteristics may be defined from experimental data and then can be used to predict decay parameters from periodical quality control performed on that same system.

The parallel first order model and second order model appear good fitting between the measured and predicted data, but the second-order model was shown to perform better than parallel first order model. However, the magnitude of difference between the two model performances is dependent both on the water quality characteristics and the experimental conditions through chlorination. As the result, it was clear that bulk chlorine decay coefficients depend on the nature of the source water and the treatment it has received.

For future research, it could attempt to predict the residual chlorine concentrations in water sample collected from water supply network and to test the second order model compatibility with hydraulic models, such as EPANET.

\section{Acknowledgement}

The authors are grateful to Dr. László Koncsos head of the Department of Sanitary and Environmental Engineering for his advice and suggestions in developing the models presented in this study. Mrs Musa Ildikó and Dr. Laky Dóra, of the Department of Sanitary and Environmental Engineering, for their guiding and assisting in laboratory test.

\section{References}

[1] Vasconcelos J. J., Grayman,W., Kiene, L., Wable, O., Biswas, P., Bhari, A., Rossman, L., Clark, R. M., Goodrich, J. "Characterization and Modeling of Chlorine Decay in Distribution Systems." AWWA Research Foundation: American Water Works Association. 1996.

[2] Clark, R., Sivaganesan, M. "Predicting Chlorine Residuals in Drinking Water: Second Order Model." Journal of Water Resources Planning and Management. 128(2), pp. 152-161. 2002. DOI: 10.1061/(ASCE)0733-9496(2002)128:2(152) 
[3] Murányi, R. " 2nd Conference of PhD students at Faculty of Chemical Engineering, Abstracts." Periodica Polytechnica Chemical Engineering. (49)1, pp. 25-89. 2005.

[4] Ribán, L., Kollár, G. "Removal of Ammonia with Biological Process in The Treatment of Drinking Water." Periodica Polytechnic Civil Engineering. 35(1-2), pp. 27-35. 1991.

[5] Yang,Y. G., Goodrich, J. A., Clark, R. M., Li, S.Y. "Modeling and testing of reactive contaminant transport in drinking water pipes: Chlorine response and implications for online contaminant detection." Water Research. 42(6-7), pp. 1397-1412. 2008. DOI: 10.1016/j.watres.2007.10.009

[6] Nejjari, F., Puig, V., Pérez, R., Quevedo, J., Cugueró, M. A., Sanz, G. Mirats, J. M. "Chlorine Decay Model Calibration and Comparison: Application to a Real Water Network." Procedia Engineering. 70, pp. 12211230. 2014. DOI: $10.1016 /$ j.proeng.2014.02.135

[7] Haas, C. N., Karra, S. B. "Kinetics of Wastewater Chlorine Demand Exertion." Journal (Water Pollution Control Federation). 56(2), pp. 170173. 1984. DOI: $10.2307 / 25042190$

[8] Clark, R. M. "Chlorine Demand and TTHM Formation Kinetics: A Second-Order Model." Journal of Environmental Engineering. 124(1), pp. 16-24. 1998. DOI: 10.1061/(ASCE)0733-9372(1998)124:1(16)

[9] Clark, R. M., Sivaganesan, M. "Predicting Chlorine Residuals and Formation of TTHMs in Drinking Water." Jounal of Environmental Engineering. 124(12), pp. 1203-1210. 1998.

DOI: 10.1061/(ASCE)0733-9372(1998)124:12(1203)
[10] Boccelli, D., Tryby, M. E., Uber, G. J., Summers, R. S. "A reactive species model for chlorine decay and THM formation under rechlorination conditions." Water Research. 37(11), pp. 2654-2666. 2003. DOI: 10.1016/S0043-1354(03)00067-8

[11] Huang, J. J., McBean, E. A. "Using Bayesian statistics to estimate the coefficients of a two-component second-order chlorine bulk decay model for a water distribution system." Water Research. 41(2), pp. 287-294. 2007. DOI: $10.1016 /$ j.watres.2006.10.027

[12] Fisher, I., Kohpaei, A. J., Sathasivan, A. "Comment on "Using Bayesian Statistics to estimate the coefficients of a Ttwo-Component second-order chlorine bulk decay model for a water distribution system" by Huang, J.J., McBean, E.A. WaterRes.(2007)." Water Research. 44(10), pp. 3309-3310. 2010. DOI: 10.1016/j.watres.2010.01.039

[13] Powell, J. C., Hallam, N. B., West, J. R., Forster, C. F. Simms. J. "Factors which control bulk chlorine decay rates." Water Research. 34(1), pp. 117-126. 2000. DOI: 10.1016/S0043-1354(99)00097-4

[14] Al-Omari, A., Fayyad, M., Al-Nimer, A. "Modelling chlorine residuals at Jabal Amman water supply." Journal of Water Supply: Research and Technology. 53(5), pp. 351-358. 2004.

[15] Fang, H., West, J. R., Barker, R. A., Forster, C. F. "Modelling of chlorine decay in municipal water supplies." Water Research. 33(12), pp. 2735 2746. 1999. DOI: 10.1016/S0043-1354(98)00519-3 